\title{
LA NARRATIVA DE LA NACIÓN EN EL DISCURSO POÉTICO MAPUCHE. PROLEGÓMENOS DE UNA LITERATURA NACIONAL ${ }^{1}$
}

\author{
Mabel García Barrera \\ Universidad de La Frontera \\ mabel.garcia@ufrontera.c

\section{RESUMEN / ABSTRACT}

En el marco de la producción discursivo/comunicativa con que el pueblo mapuche reflexiona su actual relación de contacto cultural con la sociedad chilena occidental, este trabajo aborda la construcción de una narrativa de la nación mapuche, específicamente a través de los procesos de textualización del actual discurso poético. Se sostiene que esta narrativa refiere y se caracteriza por los procesos de autoidentificación del emisor textual vinculados al reconocimiento de una identidad nacional mapuche, la dimensión simbólica de un imaginario de nación, la construcción de fronteras nacionales y una orientación discursiva mayoritariamente intracultural, donde se debate la posibilidad de una emergente literatura nacional.

PALABRAS CLAVE: poesía, mapuche, narrativa, nación, literatura nacional.

Within the framework of communicative/discursive production with which the Mapuche people reflects on their current cultural contact with Western Chilean society, this article addresses the construction of a narrative of the Mapuche nation, specifically through textualization processes of current poetic discourse. It is argued that this narrative refers to and is characterized by textual transmitter's processes of self-identification linked to the recognition of a Mapuche national identity, the symbolic dimension of an imaginary construct of nation, the construction of national borders, and a predominantly intracultural discursive orientation, from which arises an ongoing debate regarding the possibility of an emerging national literature.

KEY WORDS: Poetry, Mapuche, narrative, nation, national literature.

1 Este trabajo se inscribe en el Proyecto DIUFRO DI12-004 que dirige la autora, y toma como primer antecedente la ponencia presentada en JALLA, Lima. 2004 (Memorias JALLA). 
ENTRE EL OLVIDO Y EL RECUERDO: HILVANANDO LANACIÓN

La existencia de una nación es un plebiscito de todos los días, como la existencia de un individuo es una afirmación perpetua de vida

(Ernest Renan 65)

En la Conferencia de 1882, “¿Qué es una nación?”, Ernest Renan se interrogaba por las variadas formas que había adoptado la sociedad humana a través de su historia; una nación, señalaba, es "un resultado histórico producido por una serie de hechos que convergen en igual sentido", entre los cuales puede existir o no un principio dinástico, una raza, una lengua o una religión. "Una nación es un principio espiritual resultante de complicaciones profundas de la historia"(64), cuya esencia "es que todos los individuos tengan muchas cosas en común, y también que todos hayan olvidado muchas cosas" (57); un proceso, donde lo comunitario se encuentra en la posesión de un rico legado de recuerdos, el consentimiento de vivir juntos y la voluntad de seguir haciendo valer la herencia que se ha recibido, y, donde el olvido se encuentra en el deseo de borrar de la memoria las luchas por el territorio y por los principios culturales entre los grupos o pueblos que en su origen se anexan y la conforman.

Nada más actual que el texto de Renan para abordar la problemática “identidad/territorio” y “nación” en nuestros tiempos, cuando la tensión por el reconocimiento de lo propio frente a los otros -inmigrantes, desplazados, exiliados-se presenta como un conflicto relevante para la convivencia humana $y$, como consecuencia, para sus interacciones discursivo/comunicativas.

Desde este punto de vista, Renan no solo aporta a la comprensión del concepto de "nación" al vincularla a un "proceso" que tiene lugar por las "decisiones" humanas, a un asunto de cohesión de los pueblos fundada en la voluntad, sino además a una construcción argumentativa que evidencia, en última instancia, que conceptualizar "la nación" involucra hacerse cargo de una posición discursiva sobre ella, la que genera posiciones que pueden llegar a ser extremas e irreconciliables; todas disquisiciones que se hacen imprescindibles a la hora de abordar la problemática: cómo se construye la narrativa de la nación.

En este sentido, adscribo a la propuesta de Bhabha cuando señala que la narrativa sobre la nación es una forma de elaboración cultural, y una de las 
estructuras principales de ambivalencia ideológica dentro de las representaciones de la "modernidad":

Es el proyecto de Nación y narración explorar la ambivalencia del rostro de Jano del lenguaje mismo en la construcción del discurso con rostro de Jano de la nación. Esto convierte al familiar dios de dos caras en una figura de prodigiosa duplicidad que investiga el espacio de la nación en el proceso de articulación de elementos: donde los significados pueden ser parciales porque están in media res, y la historia puede estar hecha a medias porque está en el proceso de ser hecha, y la imagen de la autoridad cultural puede ser ambivalente porque está atrapada, inciertamente, en el acto de "componer" una imagen poderosa (214).

Relevar la actividad narrativa de la nación a través de los discursos es hacerse cargo de traducir y representar la experiencia humana mediante la "imagen" o "imago" que los pueblos construyen de sí en pos de un sentido mayor, la del colectivo; desde este punto de vista, la narrativa de la nación se inscribe en lo que Bhabha denomina "estrategias complejas de identificación cultural e interpelación (address) discursiva" (176) las que, según este autor, funcionan en nombre "del pueblo" o "la nación” a partir de un espectro de relatos sociales y literarios contextualizados por las problemáticas de la modernidad: la "diseminación" o "disemi-nación", un compuesto conceptual que refiere a ambivalencias y disyunciones en la relación "sujeto"/ "discurso", y donde la complejidad de elementos que cruzan este singular proceso sociocultural pone al descubierto la producción de un discurso inestable, a veces contradictorio, a veces sólidamente imbricado en su propósito, cuya condición in situ es su emergencia contextual.

Lo anterior deja en evidencia que la tarea mayor de "componer" la imagen de la nación, en este caso particular la nación mapuche, implica poner en relación dos variables: el pasado con el futuro de este pueblo y considerar la reflexión de Parekh sobre los modos en que actúa el nacionalismo desde sus dos caras:

El deseo estatal de volverse una nación es tan sólo el reverso de -y ni moralmente superior ni políticamente menos dañino que- el deseo de la nación de volverse un Estado"(104), donde la nación pre-política -el caso mapuche- "acentúa sus bases raciales, étnicas o etnoculturales"(105), lo que implica un proceso opuesto a la conformación del Estado que busca volverse nación -el caso chileno- 
donde se "necesita explorar modos de convertir su pueblo más o menos heterogéneo en una nación (105).

Las tensiones por el logro, en un caso u en el otro, rara vez se dan sin el "otro" que forma su contraparte, suscitando movimientos antagónicos en distintas esferas del sujeto y del colectivo, sobre todo cuando existe un largo proceso de contacto cultural marcado por relaciones de dominación y de violencia hegemónica; marco en el cual las problemáticas y la construcción de las fronteras culturales se definen en torno a dimensiones fundamentales de la vida humana que se deben evaluar en la experiencia de re-construir nación, como en la situación mapuche: la reconstrucción de la identidad -problema ontológico-; la recuperación de un espacio territorial y simbólico -problema político-; la rearticulación del modo de pensar y del conocer -problema epistemológico-; la rearticulación de los principios vinculantes y creativos de la cultura -problema ético y estético-, entre otros; ámbitos que actualmente son objeto de un desarrollo activo por parte de este pueblo al impulsar continuas propuestas de endoculturación ${ }^{2}$.

En este proceso de constituir una nación, junto al acontecimiento, la narrativa histórica resulta fundamental para efectos de la cohesión interna del colectivo y de la visibilización de cuerpo ante sí mismo y ante el otro, lo que en el caso mapuche lleva a establecer algunos campos de reflexión surgidos de esta construcción narrativa, como son: un proceso de autoidentificación vinculado al reconocimiento de una identidad nacional mapuche, la dimensión simbólica de un imaginario de nación, la construcción de las fronteras nacionales, y la emergente posibilidad de una literatura nacional; instancias que en su conjunto apoyan la emergencia de un texto con identidad propia y diferenciada que, en el marco del actual movimiento etnonacional ${ }^{3}$,

\footnotetext{
El establecimiento estratégico de distintos modos de organización en el radio urbano como en las comunidades refiere a una rearticulación global progresiva. Solo por nombrar algunas organizaciones no tradicionales: Comunidad de Historiadores mapuches, Comunidad de comunicadores mapuches, Colectivos de arte y poesía, organizaciones de estudiantes mapuches en diversos territorios ancestrales, colectivos de educadores mapuches, la comunidad lingüística, entre muchas otras organizaciones políticas, de desarrollo económico y turístico, y las cada vez más constantes alianzas territoriales.

Cfr. José Marimán, en su libro Autodeterminación. Ideas políticas mapuche en el albor del siglo XXI, quien hace una revisión detallada sobre las distintas concepciones teóricas con que se han descrito las posturas y orientaciones del movimiento mapuche; entre ellas, el movimiento "etnonancional" (65-109).
} 
narrativiza la construcción y expansión de la frontera cultural y política de este pueblo en el espacio hegemónico.

\section{LA NARRATIVA DE LA NACIÓN MAPUCHE: ARTICULACIONES ENTRE LO POLÍTICO Y LO MÍTICO}

Quinientos años después de su encuentro con Occidente y haciéndose cargo de su propio devenir histórico, el pueblo mapuche transita desde la resistencia cultural a un proceso todavía más complejo: el desprendimiento epistémico (Mignolo 23-24), como posibilidad de regreso a lo propio y a una incierta autonomía política y cultural.

En esta dirección, la revisión y reorientación estratégica de las nuevas prácticas fronterizas se articulan a partir de dos topos axiales que sustentan sus argumentos discursivo/comunicativos: "lo político", como aprendizaje y marco de entendimiento de los conceptos y prácticas sobre un estado de "orden" y de "autoridad", que ha apropiado de la cultura occidental; y, "lo mítico" como base epistémica propia, devenida de la cultura mapuche ancestral que, desde una base ética, fundamenta comprehensivamente las acciones tendientes a acentuar la diferencia cultural (García y Mora 142-143).

Evidentemente, ambas categorías, lo político y lo mítico, se intersectan, modelan y juegan sus posiciones para operar performativamente de acuerdo con intenciones individuales y/o colectivas en la construcción de la nación $y$, por ende, en su modo de narrativizarla.

En este sentido, "lo político" es un concepto referencial para el pueblo mapuche en la medida en que su aplicación por parte del Estado-nación chileno no solo ha afectado todas sus prácticas al introducirlas en un marco legal ajeno, sino además le ha permitido debatir si su organización tradicional puede ser reconstituida en el contexto intercultural bajo el concepto de lo tradicional-ancestral mediante "lof" y "ayllarewes", o bien puede adquirir una nueva perspectiva, la del Estado mapuche.

Desde este punto de vista, el año 1998, Hugo Carrasco observaba este proceso como una de las utopías del pueblo mapuche:

Este grandioso proyecto incluye en sí mismo la vigencia de la autoridad tradicional, la independencia absoluta y en particular la recuperación del territorio que fue propio, todo lo cual se funda y vertebra transversalmente en elementos como la lengua y sus discursos 
propios o etnoliteratura, el sistema de creencias y en cierto modo el arte mapuche en su sentido más amplio de oficio y saber tradicional... Este mito, entre otras cosas, orienta gran parte de la actividad política de las comunidades, organizaciones, movimientos e instituciones mapuche actuales... (1).

A dos décadas de este debate y donde los conflictos del contacto cultural se han radicalizado, los líderes del movimiento de autonomía han buscado consolidar la etapa nacional ${ }^{4}$, la que el pueblo mapuche resignifica de su pasado por dos causas: por constituir el tiempo anterior su modo referencial y porque busca cerrar el estado de suspensión histórica en que fue puesto su ethos cultural ancestral debido a la intervención foránea.

Este regreso al pasado genera algunas lecturas simultáneas sobre el proceso de autoidentificación: ser "mapuche" como pueblo/nación, provenir de un "tuwun" -territorio- y de un "küpalme" -linaje-; lo que recuerda el tránsito complejo de una comunidad étnico-cultural cruzada por diversos orígenes -nagche, huilliches, rankvlche, cadiche, pehuenches, pikunche, wenteche, tewelches, lafkenches; o mapuche del puel mapu respecto del huillimapu (Argentina/Chile)-, y que alude a antiguos y diversos territorios, linajes, dialectos, modos y roles ceremoniales; que hoy, además, integra el origen urbano -el mapuche warria (ciudad), warriache o "el mapurbe”-, tal como refiere el concepto creado y difundido por el poeta David Aniñir en su libro Mapurbe. Venganza a raíz: "Somos mapuche de hormigón/ Debajo del asfalto duerme nuestra madre/ Explotada por un cabrón/..." (33), haciendo eco de la migración forzada que los mapuches debieron realizar hacia las ciudades por la pérdida de su territorio.

La reminiscencia sobre quiénes son los mapuches es una interrogante bastante actual en las conversaciones del autorreconocimiento territorial, donde la relación milenaria entre estos grupos diferenciados dejó de ser un debate para establecerse como una aspiración de unidad cultural y territorial, cohesionada y transformada a su vez por los procesos de dominación hegemónica.

$4 \quad$ Cfr. Comunicado Público de la CAM del 13 de enero de 2013. "Nuevamente, reafirmamos nuestro Proyecto Político Estratégico basado en la Resistencia y la reconstrucción de la Nación Mapuche respaldando la defensa del Wallmapuche frente a la inversión capitalista y los procesos de recuperación territorial, siendo el Control Territorial la forma de llevar a la práctica ambos objetivos”. 
Por otra parte, esta mirada hacia el pasado permite recordarle al pueblo mapuche que "la nación mapuche" no solo es un concepto surgido desde el actual movimiento de resistencia cultural; su reconocimiento como pueblo independiente estuvo también en el discurso y la práctica política del "otro", del español primero y posteriormente en los fundadores del Estado nación chileno, antes de que éstos anexaran por la fuerza el wallmapu -territorio-, tal como lo evidencia la carta dirigida por Bernardo O'Higgins al pueblo mapuche en 1819:

Araucanos, cuncos, huilliches y todas las tribus indígenas australes: ya no os habla un Presidente que siendo sólo un siervo del rey de España afectaba sobre vosotros una superioridad ilimitada; os habla el jefe de un pueblo libre y soberano, que reconoce vuestra independencia, y está a punto a ratificar este reconocimiento por un acto público y solemne, firmando al mismo tiempo la gran Carta de nuestra alianza para presentarla al mundo como el muro inexpugnable de la libertad de nuestros Estados (3).

La posterior construcción y cohesión del Estado nación chileno cambia el giro de esta visión política al instalar un modo de relación hegemónico y de dominación cultural a inicios del año 1852 bajo la administración del presidente Manuel Montt (Pinto 124). Desde aquel período al presente, el Estado articula distintas estrategias de subyugación que transitan entre la asimilación, la integración o la exclusión, las que ponen el conflicto como base de la relación de contacto cultural chileno/mapuche.

En el marco de estas relaciones asimétricas, insertos en el proceso de transculturación pero con la conciencia de ser mapuche, avanzado el siglo XX el debate sobre la recuperación de un modo propio de "orden" sociocultural hace eco en la producción discursivo/comunicativa de este pueblo, fundamentalmente a través de la implementación estratégica de diversos discursos y metadiscursos que buscan articular un "sistema de comunicación intercultural propio” (García Entre-textos 67), el que actúa y se visibiliza como un mecanismo de cohesión al territorializar una sola "voz" ante el "otro".

La producción discursiva del pueblo mapuche se convierte en un espacio simbólico de las relaciones de contacto cultural, el que puede ser leído como un entramado complejo de estrategias, significados e interpretaciones en cuyo trasfondo se encuentra la reconstrucción de la historia mapuche. En este sentido, el discurso adquiere un estatus epistemológico al establecerse 
simultáneamente como: una vía explicativa de los acontecimientos del despojo de la tierra/territorio y de la minorización cultural y territorial, y una vía de rearticulación del quiebre de la unidad política anterior y de su proceso de desterritorialización.

La conciencia de este proceso da origen a un estado de mundo donde el mapuche se inserta reconociéndose -lo comunitario-, y donde se excluye -la comunidad obligada, parafraseando a Anderson-; consecuentemente, el discurso político, el discurso periodístico, el discurso literario, el discurso gráfico y visual, el discurso musical, entre otros, se erigen atravesados por una misma posición enunciativa que busca explicitar la diferencia cultural, acentuar la identidad mapuche y excluirse del nominativo "chileno".

En este sentido, la actual poesía ha sido uno de los discursos más estables en la construcción y visibilización de una narrativa de la nación mapuche, como lo deja entrever uno de los primeros poetas de este pueblo, José Santos Lincomán, lonko mayor de la Buta Chilhue Mapu:

Saludo a mi pueblo querido/ saludo a la tierra mía/ tierra que sin alegría/ sólo cultiva el dolor,/solo esperando el albor/ que llegará algún día/ con su montaña y su flor... No queremos tiranía/ ni menos opresión,/ queremos una nación/ ¡libre su soberanía!... (117).

Este texto, como otros anteriores a la década de los noventa (Rosendo Huenumán, Sebastián Queupul, Pascual Painemilla, por ejemplo), se ubica en la brecha de una narrativa que apela a la nación como deseo de pertenencia al interior de la ambivalencia identitaria que provoca la trasculturación, un lugar donde el sujeto poético a veces se identifica con la nación chilena y con ámbitos específicos de sectores socioculturales o políticos de ella-el mundo de los obreros, de los campesinos, de la ruralidad, de la reforma agraria, entre otros- 0 , a veces, como perteneciente a una nación cultural mapuche la cual busca transformar en nación política.

Esta ambivalencia originada en un contexto complejo de imposición cultural, más allá de narrativizar un proceso de inestabilidad en la autoidentificación nacional, produce una poesía en constante experimentación canónica al interior del canon occidental, lo que ha permitido ubicarla dentro de la institucionalidad literaria chilena (Carrasco Aportes 84).

Sin embargo, los proyectos poéticos posteriores a 1990 se insertan in situ en la definición y construcción del imaginario de la nación mapuche o de conceptos fronterizos colindantes (patria, país, Estado, pueblo, entre 
otros), imaginario que progresivamente va cobrando vida a través de los múltiples discursos que produce el movimiento mapuche, proceso donde se recuperan y resignifican los estadios simbólicos, míticos y rituales de la cultura ancestral, a la par de narrativizar una compleja contingencia que se evalúa como obstáculo de este anhelo.

Desde este punto de vista, la nación es a la vez una narrativa que trae al presente los hilos del pasado y los hilvana en torno a un posible futuro, abriendo el espacio discursivo a debates fundamentales sobre la "tierra/territorio" y la “desterritorialización”, a problemáticas sobre la alteridad y la (re)construcción de las fronteras geopolíticas y culturales, a una revisión constante de lo propio estratégicamente inscrito a partir de variados discursos como el discurso de la memoria, el discurso testimonial, el discurso de la crónica y/o tópicos, como el linaje, el despojo, el desarraigo o la marginalidad. Todos elementos que dan vida a esta narrativa, y cuyos disímiles y variados puntos de vista son cohesionados también por identificadores, como los deícticos, que señalan los símbolos de la comunidad nacional y que se forjan a partir de procesos de homologación con las naciones modernas.

Tal como podemos observar en "Konakül" -cantos del guerrero- del poeta Cristian Antillanca, la construcción de la nación mapuche es la doble cara del día/noche, solo que en este caminar el conflicto, la oscuridad y el sacrificio parece connatural:

Aquí estamos/ entre estas cuatro paredes/ contra la muerte en la cara/ frente a tu cuerpo que es universo boca arriba/ donde se han detenido todos los ríos/ donde se precipitan todos los mundos/ Mientras tú pasas el río celeste/ a caballo y con una bandera/ como una forma de llevar contigo/ todos los que aquí sangran/ Acá oscurece hermano mío/ allá/ estoy seguro/ están cantando los gallos (131).

La construcción y/o inscripción de la imagen del guerrero instala el mito del "weichafe" que, para el pueblo mapuche, se inscribe en la lógica de los linajes donde los espíritus renacen para completar el ciclo de la vida, y, en el caso particular de estos guerreros que luchan y dan la vida por su pueblo, su transformación en un "pillan”. Si la nación política necesita difundir mitos, también necesita concretar los emblemas de la nación; surge entonces la simbólica del contacto cultural donde se encuentra "wenufoye" -canelo del cielo-, la bandera creada por El Consejo de Todas las Tierras el año 1992, la que desde el año 2010 logra su reconocimiento legal y se legitima como emblema de la nación mapuche. Junto a ella también se inscriben elementos 
de la cultura ancestral como el kultrung, la txutxuka, el trarilonko y las joyas de plata, los cuales paradójicamente refieren a los símbolos que el imaginario del conquistador difundió sobre el mapuche en la construcción de su estereotipo; a lo anterior se agregan elementos de lucha espiritual en lo ceremonial como las lanzas de colihue, el küllküll y los wiños, ahora resignificados como elementos de guerra frente al winka -occidental-, y sobre lo anterior, el witrowe -especie de boleadora-, un elemento funcional que cumple la doble función de proveer alimento y la defensa.

Expresados estos emblemas y símbolos mediante "ül” -canto tradicional-, como se puede apreciar en el texto de Segundo Jara Calvún a inicios de 1900:

Kúlapang, Külapang/ El más grande, Külapang/ Qué valiente, Külapang/ Mientras hayan coligües/ Tendremos lanzas, Külapang/ Para detener al español/Külapang, Külapang (35),

o actualmente a través de la poesía escrita, como en el texto de Ricardo Loncón:

...Tú, Chileno codicioso de poder/ con engañosa lengua cruzaste la frontera/ cañoneaste sin piedad mi libertad./ Caí yo Mapuche, enarbolando mi lanza/ la razón.//Nación mapuche, del Bío Bío hasta el Toltén/ gritó mi sangre./ Escucharás allí por siempre, voces de Kullkull/ sonidos de kultrún, ruidos de lanza/ como una maldición en tus oídos... (s/f),

el discurso poético mapuche ha establecido al interior del tópico del "conflicto histórico" una línea de legitimación y visibilización de los héroes que forjan la nación.

Caracterizados por su fuerza, valentía y liderazgo, los primeros guerreros han permanecido en la memoria cultural porque lograron detener al conquistador marcando la línea fronteriza. Leftxaru, Caupolicán, Kalfukurra, Kilapang, Pelantaru, o Guacolda se transforman en imágenes referenciales que la poesía retoma reelaborando el mito que fue inscrito una vez en la oralidad.

Desde este punto de vista, los poetas José Santos Lincomán, Anselmo Raguileo, Rosendo Huenuman, Elicura Chihuailaf, Leonel Lienlaf, Rayen Kvyeh, María Huenuñir, Eliana Pulquillanca, Juan Paulo Huirimilla, Luciérnaga Pinda, María Teresa Panchillo, entre otros, textualizan la conexión entre el nag mapu -tierra de los hombres- y el wenu mapu -la tierra de arriba- apertura donde el hablante lírico convoca y/o es convocado por el "newen"-fuerza o poder- y el "püllu" -espíritu- de estos antiguos weichafes, tal como lo refiere Lienlaf en el poema "El espíritu de Lautaro": 
Anda cerca de la vertiente/ bebiendo el agua fresca/ y grita en las montañas/ llamando a sus guerreros// El espíritu de Lautaro/ camina cerca de mi corazón/mirando/ escuchando/ llamándome todas las mañanas// Lautaro viene a buscarme,/ a buscar a su gente/ para luchar con el espíritu/ y el canto// Tu espíritu Lautaro/ anda de pie/ sobre esta tierra (41).

Aludiendo a la renovación de las fuerzas, a través de los versos: “Anda cerca de la vertiente/bebiendo agua fresca”, y al poder de este espíritu sobre el pueblo mapuche y sobre el propio hablante lírico -al buscar la transformación de éstos en otros "weichafe"-, el poema de Lienlaf inscribe una lectura cultural sobre el proceso de resistencia cultural.

El discurso poético mapuche no solo mira hacia el pasado heroico, también narrativiza los acontecimientos contemporáneos, donde los nuevos héroes -Jhonny Karikeo, José Huenuche, Alex Lemún, Matías Catrileo, José Mendoza Collío, entre otros ${ }^{5}$ - emergen como prototipos de la lucha mapuche simbolizando un solo linaje, el del pueblo mapuche. Poetas como Jaime Huenún, Eliana Pulquillanca, Rayen Kvyeh, Carlos Levi, Erwin Quintupill, Marta Trecaman, Elicura Chihuailaf, Jaqueline Caniguan dialogan con estos acontecimientos a través de sus proyectos escriturales, ya sea mediante la poesía o los metadiscursos.

El texto "Ü1 de Catrileo" del poeta Jaime Huenún refiere a esta compleja relación del discurso con el metadiscurso, al resignificar el diálogo de los comuneros mapuches transmitido por la Radio Bío Bío el día que mataron a Catrileo:

No entregaremos el cuerpo, no:/ esta es la muerte que nos dejan,/ las balas que cortaron el amanecer/ el río de Matías Catrileo/ en Vilcún./ Pero el volcán Llaima arde por ti/ y la ceniza de tus ojos ocultos/ escribe la nieve/ la rabia y el misterio/ de un pueblo ya sin bosques y sin armas,/cercado por tanquetas y bombas lacrimógenas,/ sentado en el banquillo del Juzgado de Indios/ de la modernidad... (156).

Se inscribe aquí una conexión transtextual al interior del proyecto poético, el que a su vez busca articularse con otros textos -poéticos y no poéticos

5 Comuneros mapuches que han perecido defendiendo o tratando de recuperar sus tierras de la agresiva irrupción de las forestales, hidroeléctricas o de la ocupación colonizadora que avaló el Estado chileno. 
(como la resignificación que hace el grupo musical Wechekeche ñi trawun de la misma transmisión radial) - y otros metadiscursos (como "Carta abierta desde el país mapuche” del mismo Huenún sobre este acontecimiento), estableciendo una circularidad dialógica que territorializa el espacio público desde la denuncia.

La cercanía de estos acontecimientos genera una impronta emotiva en este discurso, cuya característica es una fuerte expresión de dolor, rabia o sentimiento de injusticia, y donde el texto junto con adquirir una función metacognitiva y especular orientada a la evaluación del proceso histórico, se dirige al receptor buscando en él un modo de anclaje a esta vivencia.

Si lo político actúa vinculado a estos argumentos y otros que seguramente se escapan a esta mirada, lo mítico se establece con una doble lectura: como dispositivo epistémico de la cultura mapuche ancestral, tal como lo he señalado anteriormente, y como construcción cultural, dando origen a un discurso que organiza un conjunto de figuras referenciales "que proveen a sus miembros de las coordenadas de su pertenencia geopolítica" (Landowski 68) y a lecturas que, entrelazadas, crean una cadena de significados y estadios simbólicos perfectamente cohesionados en soportes éticos que justifican las posiciones y acciones de recuperación y resistencia cultural y/o de desprendimiento epistémico.

Desde este punto de vista, lo mítico, en su doble acepción, inscribe los elementos de la cultura ancestral de manera iterativa en la narrativa de la nación, principalmente a través del mecanismo de "retradicionalización cultural" (García El proceso 51-68), lo que podemos observar en cada uno de los textos citados anteriormente, y también en la mayor parte de los poemarios publicados desde la década de los noventa a la fecha, como también en los proyectos iniciales de jóvenes poetas:

Tengo las lunas pegadas al pecho/y un incesante kultrun como banda sonora/no te distraigas Kintuante.../Te rondan pies descalzos y transparentes/sabias arrugas enrutan tu cauce/resiste Kintuante...// Se desprenden de tus venas/verdes colores en caudales/no te duermas Kintuante/la sangre no siempre es roja...//Moja nuestros piuke/con dulce agua/rompe de tus orillas las cadenas/no te inundes Kintuante// No te distraigas/ni te duermas/ni te inundes/Resista señor Kintuante!!! ${ }^{6}$.

6 http://tiamatkarlita.blogspot.com/2011/11/kintuante-resiste.html 25 abril de 2013] 
"Resiste Señor Kintuante" de Carla Linco tiene por contexto el último conflicto por las aguas, la construcción de una hidroeléctrica en el río Pilmaiquen, en territorio williche. Este es un poema anclado al pensamiento mítico de la cultura ancestral, que alude al "ñgen co" o dueño de las aguas mediante la inscripción de algunos versos en un ritmo similar a las fórmulas de una oración ceremonial: "no te distraigas Kintuante...resiste Kintuante...no te duermas Kintuante...no te inundes Kintuante... Resista señor Kintuante”; versos que en el contexto ceremonial, por la función en imperativo, buscan transferir “newen” -fuerza o energía- al "ñgenco” en esta situación de peligro; bajo este recurso el poema se hace cargo de una práctica comunitaria tradicional sustentada en la reciprocidad, como vinculación y vehiculación espiritual indisoluble entre los seres del wallontu mapu o universo.

La narrativa de la nación mapuche, por lo tanto, es al mismo tiempo una narrativa que integra a los seres del universo mapuche coactuando como uno solo ante el "otro". En este sentido la narrativa de la nación mapuche adquiere las características de relato mítico, por una parte, por la construcción de figuras, emblemas, símbolos y coordenadas témporo-espaciales de referencia, y, por otra, porque se sustenta en el pensamiento mítico de la cultura ancestral, el que ahora, en la nueva circunstancia histórica, emerge orientado con una función política transformándose para actuar en el espacio de contacto cultural.

Esta narrativa, en el discurso poético, refiere la distancia entre el mapuche y el "otro" mediante la construcción de la frontera cultural: acentuando el idioma, instalando los elementos de una compleja y rica cosmovisión, exponiendo modos y roles de la organización tradicional, inscribiendo sus bases epistémicas y estéticas (García, La construcción 43-56), entre muchas estrategias y rasgos que buscan territorializar al texto como propio.

La diversidad de estrategias textuales en los diversos proyectos poéticos se orienta cada vez más a comunicar el proceso de autoidentificación nacional y por extensión visibilizar la diferencia cultural. Entre las estrategias más visibles se encuentra el constante uso de una paratextualidad asociada a las prácticas ancestrales, a los seres de los espacios nouménicos y a formas de comunicación sacralizadas: Ceremonias (Jaime Huenún), Oratorio al Señor de Pucatrihue (César Millahueique), Üi (Adriana Paredes), Arco de interrogaciones (Bernardo Colipan), Perrimontun (Maribel Mora Curriao), Shumpall (Roxana Miranda Rupailaf), Kütral. Instala/zión Fotopoética en Bábilon Warria (Manquepillanpaillanalan), entre otros; o, a acontecimientos que aluden a la historia del despojo territorial o de la marginación urbana: Reducciones (Jaime Huenún) o Mapurbe (David Aniñir). De este modo, la 
paratextualidad se hace cargo de una enunciación simbólica que territorializa el texto desde el título del poemario, demandando una competencia intracultural.

Los proyectos escriturales y el arte mapuche en general dejan entrever un deseo vehemente por enunciar y territorializar la condición de pertenencia al pueblo mapuche; así, el título se convierte en un gesto que es reafirmado por epígrafes, oraciones tradicionales, subtítulos de los poemas, títulos de los apartados interiores, fotos e imágenes; constituyendo una cadena recursiva de significados y significantes en torno a asegurarle al "otro" la identidad diferenciada del dueño de la palabra, y de paso, se busca invertir el histórico proceso de "reducción de la voz indígena" (Lienhard 10).

\section{NARRAR “LASDISTANCIAS”ENELBICENTENARIODELESTADO- NACIÓN CHILENO}

Recogiendo la estrategia enunciativa de poemarios referenciales, como En el país de la Memoria de Elicura Chihuailaf, Se ha despertado el ave de mi corazón de Leonel Lienlaf, Luna de los primeros brotes de Rayen Kvyeh o Walinto de Graciela Huinao; surge el año 2010, en el marco del Bicentenario del Estado-nación chileno, Las distancias de Erwin Quintupill, uno de los textos más enfáticos en visibilizar la brecha fronteriza que se establece entre las dos identidades nacionales en conflicto. Un texto que, mediante una retórica de la comparación, se centra en destacar cómo se ha construido la identidad nacional chilena asentada en el despojo de los elementos culturales y territoriales mapuches.

Señala en la introducción al poemario:

Surge este libro de modo urgente, en un lenguaje que no me es común. Es la necesidad de los tiempos que vivimos. La porfía de los herederos chilenos obliga a golpear con la palabra, aunque a la mayoría de ellos les parezca una insolencia. Este es un llamado a que no nos hagan partícipe de su fiesta, a que se atrevan a decir la verdad a sus conciudadanos.

Este mensaje va, entonces, preferentemente a los que gobiernan, a los que deciden la legislación, a los creadores del curriculum enseñado en las escuelas, a los que imponen -aun en estos días- sus viejas ideologías, enarbolando sus insignias y cruces gastadas. A los que compraron la tierra ensangrentada no les digo nada. Ni a ellos, ni a sus defensores. 
Siquiera, déjennos vivir esta vergüenza en silencio, aunque algunos no podamos (3).

Las distancias es un largo diálogo organizado como contradiscurso, que resignifica los símbolos y emblemas de la patria: los de la nación chilena; la que observada desde el relato testimonial o de la voz-palabra expone las heridas del despojado.

Compuesto por veinticinco poemas distribuidos en cincuenta páginas, este poemario se divide en cuatro partes: "Himno Nacional de Chile”, "La bandera chilena”, “Los héroes de Chile” y "El escudo”.

En "Himno Nacional”, los respectivos poemas se despliegan en el texto a partir de un título propio, los que corresponden en este primer apartado a cada uno de los versos del himno nacional de Chile. A través de estos poemas, se narra la constitución de una patria asentada sobre nobles ideales -argumentos desplegados en los títulos- los que, a lo largo de la práctica sociocultural nacional, han quedado fijados en actos y significados reprobables -argumentos desplegados en el cuerpo central de cada poema-.

Simbolizados a través de las marcas textuales, esta reflexión crítica cubre un amplio espectro de tópicos: la pérdida del paraíso, la inocencia del hombre primigéneo, la instalación de basurales en las comunidades, el daño a la capa de ozono, la deforestación, la modernidad y sus artefactos:

Así fue en otro tiempo/oculto para tus ojos de niño bueno/ahora hay bolsas con basura abandonadas en nuestros caminos/ahora el sol duele/y las praderas desnudas se exponen a la lluvia/ahora hay cuerpos extraños en la tierra/Ni los muertos descansan en paz (Puro, Chile, es tu cielo azulado 6).

Los argumentos formulados se observan desde distintos ángulos, a los que se agregan otros con el objetivo de demostrar una pluralidad de acciones orientadas, por el chileno, hacia un mismo fin: la degradación del medio ambiente, la expansión territorial hacia el espacio exterior, el poder económico y la consecuente pobreza y miseria, la instalación de represas y el cerco a las aguas, la muerte del mapuche, la imposición de la religión cristiana, entre otros:

Hay carreteras en el espacio/ Corre-Chile-por tus vientos más altos/ el dinero de los dueños. / Lo que fue puro alguna vez/ lo rompe el norte/ Quedan colgajos de ozono sobre la región más austral./ Mis hermanos antiguos sepultados están/ Pero no en silencio./ Sólo falta que en tu amplitud/ construyan el palacio presidencial” (¿Puro, Chile, es tu cielo azulado? 7). 
Ante esta narrativa de la nación ajena, marcada por una identidad deleznable a los ojos del hablante lírico, también se narra implícitamente la identidad de la nación mapuche, la que se infiere por oposición a esta serie de descriptores y que contrasta con la del chileno.

Indio antipatriota, me dijeron, no valoras los emblemas patrios. / ¿De qué sirve educarlos si van a continuar pegados a sus/ espíritus del pasado? ¡Vuélvanse a casa, desgraciados!, faltó que/ me dijeran. // Era el día de las inauguraciones en mi patria usurpada (Dulce Patria, recibe sus votos 15 ).

Bajo una estrategia que narrativiza desde pares opuestos, en estos textos también se instalan algunos puntos de encuentro, como aquellos que unen al desvalido, chileno y mapuche, explotados por empresarios y políticos; fuera de este vínculo, la separación cultural es total.

El segundo apartado, “La bandera chilena”, instala una estrategia distinta, más lírica; donde además de inscribir títulos de acuerdo a los colores patrios: azul, rojo y blanco, y hacer una referencia a "la estrella", se integran tres poemas a modo de cuecas, aludiendo a cuecas chilenas tradicionales: "La rosa y el clavel”, "Cielito lindo”, por ejemplo, con el propósito de establecer una serie de intertextualidades con los referentes emblemáticos de la identidad nacional chilena; lectura desde la cual se produce el proceso de inversión de significados, adentrándose a la ironía.

Estos poemas o cuecas siguen una tipografía marcada por los colores patrios:

(La muerte) Se agranda Chile pa'l norte/(La muerte) Se agranda Chile pa'l sur/(La muerte) se agranda para los cielos/(La muerte) nos dejan sin pan ni luz./Me empujan pa cerros tristes/(la vida) tiempo doliente/ Quemado quedó el sembrado/(abajo) como sufriente/Como sufriente, ay no/(caramba) yo voy dudando/Si tendrán dentro 'e su pecho/(ay, ay, ay) un contrabando//Un contrabando, duele/(por el cerro) yo quisiera/Devolverte los balazos/(mi vida) en tu sesera/En tu sesera, ay no/pierdo el cariño/huyendo por barrancos/(la muerte) vi cuatro niños/Vi cuatro niños, sí/(abajo) peras maduras/Parecía un soldado/ (abajo) Pero, era cura//Pero era cura, no/(debajo) pasan los años/No quiero que con su mano/(tu vida) Me haga más daño/Me hagan más daño, sí/(parece) todo es inútil/Han entrado a mi casa/(sufriré) con su fusil/con su fusil, de nuevo/(ay, ay, ay) me quita el sueño/mientras va celebrando/(ay, ay, su) bicentenario//Toda mi alma, morena/carga consigo una pena" (Cueca roja interminable 30-34). 
En un tono elegiaco, el hablante lírico va refiriendo el progresivo destierro y reducción de su espacio vital por la expansión del territorio chileno, acción hegemónica que metaforiza a través de "(La muerte)"; así, se activa un proceso de homologación entre "Chile" y "la muerte", como una sola figura que se despliega territorializando un espacio específico que es finalmente la totalidad del espacio del "otro" -norte, sur, cielo, pan- y este avance lo hace según la imagen diagramática de una cruz: dos direcciones laterales "(La muerte) Se agranda Chile pa'l norte/ (La muerte) Se agranda Chile pa'l sur”, una dirección hacia arriba "(La muerte) se agranda para los cielos”, mientras la otra baja "(La muerte) nos dejan sin pan ni luz", donde "pan" resignifica la "mapu”, la tierra, fuente nutricia de la vida.

Es esta última orientación, la del territorio de la muerte, la que es expresada de manera reiterada a lo largo del poema: Quemado quedó el sembrado/ (abajo) como sufriente, Vi cuatro niños, sí/ (abajo) peras maduras/ Parecía un soldado/ (abajo) Pero, era cura// Pero era cura, no/(debajo) pasan los años, versos que simbolizan la opresión por los agentes del Estado nación chileno: el ejército y la Iglesia.

En medio del texto se simboliza el conflicto: Un contrabando, duele/ (por el cerro) yo quisiera/ Devolverte los balazos/ (mi vida) en tu sesera/ En tu sesera, ay no; conflicto que se observa como un robo, el "contrabando", de la tierra/territorio; ante lo cual deviene una solicitud No quiero que con su mano/ (tu vida) Me haga más daño/Me hagan más daño, sí/(parece) todo es inútil.

El hablante lírico evidenciando el cansancio de una acción reiterativa, "Cueca roja interminable" como lo indica en el título del texto, narra en los últimos versos el allanamiento a las comunidades desde una práctica hegemónica que se solaza en la indiferencia: Han entrado a mi casa/ (sufriré) con su fusil/ con su fusil, de nuevo/(ay, ay, ay) me quita el sueño/ mientras va celebrando/(ay, ay, su) bicentenario//Toda mi alma, morena/ carga consigo una pena.

El tercer apartado, "Los héroes de Chile", homologa la clasificación arquetípica de los héroes según el registro de la historia oficial; así, los títulos de los tres poemas que conforman este apartado se formulan de manera exegética, adscribiendo los dos primeros textos a los héroes del pueblo chileno y el tercer poema a los héroes del pueblo mapuche.

El primero, "Los conocidos y afamados” corresponde a aquellos héroes que perduran en la memoria por estar sus nombres escritos en los textos: 
...sus abuelos abultados de emoción/ los llamaron Cornelio, Hernán y de otros modos/ escribieron sus nombres en páginas extraídas a la cordillera/ para que permanecieran intactos/ como en el útero oculto y ultrajado del que vinieron... (39).

Mientras el segundo poema, "Los otros", corresponde a los chilenos que dejaron su sangre en la espesura de los bosques, sin que nadie los recordara.

El tercer poema, "Para el más desconocido y oculto de todos”, es la referencia a todos los propios, los cotidianos y al "pequeño gran héroe" que da la vida por su pueblo. Éstos son interpelados desde la invocación, mediante un texto poético que se establece en el cruce del canto tradicional "ül” y del discurso poético actual, lugar donde el hablante lírico adopta la función de “ülkantufe" -cantor- al expresarse en mapudungun:

Con melodía de canto ignorado te canto te nombro te hablo/ a ti que me sabes feo y hermoso// Tú que no pretendes ser la copia de mi espíritu/ que puede comprender y aceptar el misterio del lenguaje de los /vegetales// Te canto te nombro te hablo/ peñi anay peñi lamgen anay lamgen// tú que entiendes mis borracheras mis odios mi silencio/ peñi anay peñi lamgen anay lamgen//... (44).

El último y cuarto apartado, "El escudo”, se encuentra compuesto por un breve poema sin título y que por antonomasia se adscribe al título del apartado:

El huemul/ El cóndor/ La razón/ La fuerza/ La grandilocuencia/ Los colores/ La porfiada estrella blanca/ El escudo/ Las plumas teñidas de azul, blanco y rojo/ todo allí reunido/ en la nada misma/ En el más claro desentendimiento/ del origen de los elementos/ En el más claro desconocimiento/ de la naturaleza de los poderes (48).

"El escudo" refiere en sí mismo una imagen heráldica de la nación chilena que homologa linaje y sentido de pertenencia, simbolizando la frontera cultural.

Desde el punto de vista discursivo, "el escudo" actúa metonímicamente al aludir al "discurso de la nación chilena”, el que se ha construido sobre un imaginario: la tierra/territorio del otro y la identidad también tomada del otro; por lo cual este discurso sobre la nación queda reducido a la nada -en este espacio fronterizo-, porque nada lo sustenta desde la óptica del hablante lírico, ni la razón, ni la fuerza: ...todo allí reunido/ en la nada misma/ En el más claro desentendimiento/ del origen de los elementos/ En el más claro desconocimiento/ de la naturaleza de los poderes. 
De este modo, a los ojos del hablante lírico, Las distancias cifran la imposibilidad de acercar los territorios, las subjetividades, la comprensión y el entendimiento por aquellos procederes tan distintos que a lo largo del contacto cultural solo han traído la desolación y la transformación de las relaciones naturales entre los hombres y de estos con la naturaleza.

Las distancias ubica dos narrativas nacionales en vías paralelas donde, a partir de observar al "otro", se desacraliza lo sacralizado, se resignifica el mito de la nación chilena, y se invierte el lugar ético y discursivo del subordinado.

\section{DE LA NARRATIVA DE LA NACIÓN HACIA UNA LITERATURA NACIONAL MAPUCHE}

La lectura realizada a los textos poéticos, desde el ángulo de los procesos de autoidentificación nacional, no agota la amplitud ni la profundidad interpretativa sobre la narrativa de la nación mapuche, por el contrario, esta incursión sugiere algunas interrogantes que ameritan otros puntos de vista y que, por ahora, son enunciadas esperando continuar su reflexión.

$\mathrm{Al}$ respecto, la interrogante que naturalmente se desprende de este trabajo es si nos encontramos ad portas de una literatura nacional mapuche, pregunta que se realiza desde una óptica específica que busca conjugar el desarrollo histórico de estas expresiones artísticas con las distintas posiciones que refieren los proyectos artísticos sobre la relación de contacto cultural -donde se inserta el proceso de autoidentificación nacional-, visualizándose este desarrollo como un giro constante hacia la recuperación de lo propio y que comprende una fase de integración cultural a la cultura nacional chilena, una posterior posición de resistencia hasta, en esta última etapa, enfatizar el deseo por el desprendimiento epistémico de la matriz colonial de poder.

Es respecto de este movimiento que cabe debatir si las nociones o las perspectivas empleadas para describir el actual proceso artístico, específicamente literario, dan respuestas suficientes a evidencias discursivas que refieren una conciencia nacional distinta a la identidad nacional chilena.

Aquí parece ser que el punto más complejo, sobre la denominada "literatura mapuche” tal como la describe Iván Carrasco el año 1990, es por una parte, la adscripción que se realiza de ella al interior del canon literario chileno, y, por otra, el dinamismo de esta literatura al adoptar distintas fórmulas expresivas al interior del canon occidental. 
Para Carrasco, la literatura mapuche se encuentra originada en la tercera "etapa de la evolución de la textualidad artística mapuche (oralidad absoluta, oralidad inscrita y escritura propia)”, como producto de la interacción cultural mapuche/chilena, espacio donde surge

una literatura mapuche propiamente tal, es decir, una literatura escrita por autores mapuches en mapudungun, de acuerdo a las normas de la escritura artística moderna. Por lo tanto, se trata de textos conformados con categorías mapuches en su enunciación y su enunciado, aunque en la concepción de texto estén incluidas categorías no mapuches (24).

Consciente de usar una categoría occidental, como el concepto de "literatura", para dar cuenta de las producciones escritas del pueblo mapuche, el año 1994 Carrasco ha reformulado con pertinencia cultural esta denominación, reconociendo particularidades distintas a las de la cultura chilena; sin embargo, y a pesar de ello, la integra a la vertiente nacional chilena:

En síntesis, los escritores mapuches han logrado insertar en el patrimonio literario chileno un nuevo tipo de autor, bilingüe de carácter indígena, un nuevo código lingüístico, el mapudungun, y una cultura vista desde la perspectiva de sus practicantes, además de una forma nueva de lectura pública oral de poemas, marcada por la ritualidad, el canto y la traducción (85).

Esta vía de integración de la literatura mapuche en el paradigma nacional se refuerza bajo la noción de "discurso etnocultural” que el autor utiliza el año 1998 para describir un modo de expresión amplio que surge del cruce cultural entre varias culturas latinoamericanas, donde se conjugan técnicas, cánones estéticos y soportes discursivos, discurso en el cual una de sus expresiones es la "poesía etnocultural”:

La poesía etnocultural constituye la representación de la interacción de las culturas indígenas, europeas y mestizas, por tanto, la conformación de un espacio intercultural de escritura, un modelo de lenguajes, culturas y grupos étnicos en interacción en el marco de la sociedad global (51).

Según este autor, el fundamento de esta discursividad es la formación socioétnica de la sociedad chilena. 
En otras palabras, la poesía etnocultural es un discurso de reciprocidad, del diálogo interétnico, más que del combate, la negación o la separación. Creo que este sentido subyacente del discurso etnocultural sobrepasa los sentidos antiwinkas, en el sentido de aceptar la situación actual que es una convivencia estable de personas de variado signo étnico y cultural en una sociedad global menos homogénea y europea de lo que se piensa (54).

Avanzados algunos años, en su trabajo "Literatura Chilena: Canonización e Identidades" de 2005 precisa aún más la noción de "poesía etnocultural”, ubicándola en el "sector marginal" que no ha sido abordado por el proceso de canonización institucional de la literatura chilena; este sector marginal estaría: “... conformado principalmente por tres clases de texto de carácter intercultural: la poesía etnocultural, la literatura del exilio y la literatura de grupos inmigrantes" (42), los cuales, “...se insertan en una corriente de modificación y ampliación del canon de la literatura chilena..."(46)

Si interpretamos lo que ha sido este proceso de teorización, se puede argüir que ha sido un soporte epistémico valioso para relevar esta producción de parte de la crítica académica y también de parte de algunos poetas mapuches -exceptuando al poeta Elicura Chihuailaf, quien postuló el concepto de “oralitura” para dar cuenta de este particular proceso escritural que conjuga los patrones tradicionales, oralidad y canon occidental-. Sin embargo, en esta misma dirección se puede observar que, más allá de reconocer y valorar las características propias de la producción escrita de los poetas y narradores mapuches, ésta se realiza bajo el prisma de la institucionalidad literaria vigente, repitiendo una visión integracionista al adscribir esta producción a la literatura chilena: una literatura nacional.

Es en esta orientación donde cabe discutir, veinte años después de que surgiera la noción de "literatura mapuche”, sobre la pertinencia de su adscripción.

En este sentido, cabe revisar argumentos que apelan por una lectura más émica sobre este proceso escritural, una de ellas es la que realiza el año 1999 Rolf Foerster en “¿Movimiento étnico o movimiento etnonacional mapuche?”, donde refiere el concepto de "literatura mapuche" anclada a una narrativa de la nación, toda vez que ella se hace cargo de expresar una conciencia nacional:

Posiblemente los poetas mapuches y huilliche -Elicura Chihuailaf, Leonel Lienlaf, Bernardo Colipan, César Millahueique, Jaime Huenún, Ricardo Loncón, entre otros- se molestarían si los calificáramos de estar promoviendo una suerte de nacionalismo mapuche. Pero, ¿qué 
duda cabe que ellos han sido los primeros en producir un nuevo orden del discurso para la sociedad mapuche-huilliche contemporánea? No se trata solamente de un lenguaje que vuelve sobre las heridas del pasado, sino que es capaz de crear un espacio discursivo que reposiciona la tradición mapuche en el nuevo escenario cultural. En esta tarea los poetas mapuches transitan desde la oralidad hacia una literatura mapuche. Si la nación es una narrativa, no dudamos, al leer sus poemas, que allí se encuentra una parte importante de su simbólica (54).

Evidentemente nos encontramos ante una problemática compleja que amerita una rigurosa discusión, sobre todo porque en la base de esta distinción normalmente se introduce un rasgo argumentativo que apela por la pureza cultural, situación no menos compleja cuando en el proceso de contacto cultural, como el caso mapuche/chileno, se implican variados factores de préstamos culturales debido a la transculturación obligada que le imprime el sistema hegemónico. Ante este cuestionamiento podríamos estar de acuerdo con la reflexión que hace José Carlos Mariátegui en su ensayo de 1928, "El proceso de la literatura", para quien "el concepto de literatura nacional" refiere a un concepto complejo que traduce una serie de imbricaciones, entre ellas, aludiendo a Sanctis, las influencias en el origen de su formación, como: en la poesía griega, la influencia asiática; en la latina, la griega; y, en la italiana, la griega y la latina; y, aquí se podría agregar que en la chilena, todas las anteriores y además la indígena; como en la mapuche, su propia vertiente además de la europea.

La actual poesía mapuche, y el arte mapuche en general, en su desarrollo ha caminado por diversas rutas que la entroncan con la tradición mapuche ancestral y la occidental, como lo ha expuesto Maribel Mora Curriao en su Prólogo a Kümedungun/Kümewirin. Antología poética de mujeres mapuche (siglos $X X-X X I$ ); sin embargo el proceso de recuperación y reafirmación cultural que realizan los artistas transparenta un texto cada vez más empoderado en lo propio, lo que no significa reificación, estaticidad o exclusión de los movimientos artísticos universales. Hay que recordar que una de las características relevantes de la cultura mapuche es su gran capacidad de adopción y adaptación de los elementos culturales ajenos en función de lo propio.

En este proceso, el uso del mapuzungun, originando textos bilingües, de los lenguajes ancestrales como el "pewma” y el "perrimontun”, y de elementos ceremoniales que territorializan el texto y a su vez enmascaran los elementos occidentales, ha abierto un camino hacia lo relevante y fundacional: la 
constitución de un sistema de arte mapuche actual (García, Estrategias 283301), donde la literatura como las demás expresiones recuperan y resignifican las bases epistémicas y estéticas de la cultura mapuche ancestral (García, La construcción 43-56), mediándolas con las bases estéticas indoamericanas y occidentales (García, Ponencia 2013), dando origen a un texto con identidad propia y diferenciada.

En este sentido, situar una literatura nacional en un contexto hegemónico no es solo tematizar y simbolizar la nación, es sobre todo establecer un complejo dispositivo que la legitime al interior de un sistema canónico propio, el que inevitablemente ha surgido vinculado a las problemáticas de la alteridad (como en toda las literaturas nacionales), donde el "otro" externo es gradualmente desplazado por el "otro" del cual se forma parte.

Como ha señalado Frantz Fanon en Los condenados de la tierra, en la etapa de conformación de una literatura nacional el giro de la textualidad transita naturalmente de un receptor general a uno más específico, en este caso hacia el propio pueblo mapuche:

La cristalización de la conciencia nacional va a transformar los géneros y los temas literarios y, al mismo tiempo, a crear un nuevo público. Mientras que al principio el intelectual colonizado producía exclusivamente para el opresor, sea para halagarlo o para denunciarlo a través de categorías étnicas o subjetivistas, progresivamente adopta el hábito para dirigirse a su pueblo...Sólo a partir de ese momento puede hablarse de literatura nacional. Hay, en el plano de la creación literaria, reformulación y clarificación de los temas típicamente nacionalistas... (220).

En este sentido, metafóricamente lo que se acentúa es el carácter de "lo nuestro”.

En esta misma línea, los aportes de Castany-Prado resultan clarificadores aunque no exentos de cuestionamientos en la fijeza de una noción a la que busca poner límites para desvincularla de la actual y cosmopolita "literatura posnacional”.

Podemos llamar "nacional” a aquel tipo de obras literarias que incluyen de forma implícita una cosmovisión nacionalista. Serán obras que suelen considerar que la propia nación es la única realidad de la que deben y pueden dar cuenta; que cada cultura o sociedad nacional es autosuficiente; o que la responsabilidad moral no tiene más alcance que el que marcan las fronteras de su propio país (168). 
Estando conscientes de que lo anterior es una reflexión primaria, a lo menos podemos dejar planteado que no está en discusión si la expresión artística tradicional ancestral es una expresión propia de la nación mapuche.

\section{BIBLIOGRAFÍA}

Anderson, Benedict. Comunidades Imaginadas. Reflexiones sobre el origen y la difusión del nacionalismo. Buenos Aires, Argentina: Fondo de Cultura Económica, 1993.

Aniñir Quilitraro, David. Mapurbe. Venganza a raíz. Primera edición. Talleres Gráficos "El Sindicato". Santiago, Chile: Producción editorial Lord Carter (La Lle’a), 2005.

Antillanca, Cristian. “Konakül”. Weichapeyuchi ül: cantos de guerrero. Antología de poesía política mapuche. Ed. Paulo Huirimilla. Santiago. Chile: LOM Ediciones, 2012.

Bhabha, Homi. “Narrando la nación”. La invención de la nación. Lecturas de la identidad de Herder a Homi Bhabha. Buenos Aires, Argentina: Manantial, 2000. 211-219.

Carrasco M., Iván. “La poesía etnocultural: modelo de una sociedad en diálogo”. Lengua y Literatura Mapuche 8, 51-61. Temuco, Chile: Universidad de La Frontera, 1998.

“Aportes de la textualidad mapuche a la literatura”. Lengua y Literatura Mapuche 6, 83-90. Temuco, Chile: Universidad de La Frontera, 1994.

“Etnoliteratura mapuche y literatura chilena: relaciones”. Actas de Lengua y Literatura Mapuche 4, 19-27. Temuco, Chile: Universidad de La Frontera, 1990.

“Literatura Chilena: Canonización e Identidades”. Estudios Filológicos 40, 29-48. Universidad Austral de Chile, 2005.

Carrasco, Hugo. “La utopía étnico-cultural en la poesía mapuche de Chile”. Ponencia presentada en el III Seminario Internacional de Literatura, Pontificia Universidad Católica de Temuco. Temuco, Chile. (s/p), 1998.

Castany-Prado, Bernat. Literatura Posnacional. Universidad de Murcia, Murcia, España: Ediciones Editum, 2007. 342.

Fanon, Frantz. Los condenados de la tierra. México: Fondo de Cultura Económica, 1963.

Foerster, Rolf. “¿Movimiento étnico o movimiento etnonacional mapuche?”. Revista Crítica Cultural 18: 51-59, 1999.

García, Mabel y Selva Mora. "El discurso político en el ámbito de la comunicación intercultural”. Lenguas y Literatura Mapuche 7: 139-149. Departamento de Lenguas y Literatura. Temuco, Chile: Universidad de La Frontera, 1996.

García, Mabel. "Entre-textos: la dimensión dialógica e intercultural del discurso poético mapuche” Revista Chilena de Literatura 72. Departamento de Literatura, Universidad de Chile, 2008.

"Estrategias del discurso artístico mapuche como proyecto de autonomía estéticocultural”. Sociedad, cultura y literatura. Arcos Cabrera Editor. FLACSO y Ministerio de Cultura del Ecuador. Quito, Ecuador, 2009. 
"La construcción del relato mítico ancestral en el arte y la poesía mapuche actual”. Papeles de Trabajo 20. Universidad Nacional de Rosario, Argentina, 2010.

"El proceso de retradicionalización cultural en la poesía mapuche actual: Üi de Adriana Paredes Pinda”. Revista Chilena de Literatura 81. Departamento de Literatura, Universidad de Chile, 2012.

"De la narrativa de la nación mapuche a un arte nacional”. Ponencia presentada en el I Congreso Internacional: Nuevos horizontes de Iberoamérica CILHA. 6, 7 y 8 de noviembre de 2013. Universidad Nacional de Cuyo. Mendoza. Argentina.

Huenún, Jaime. Reducciones. Santiago, Chile: LOM Ediciones, 2012.

Jara Calvún, Segundo. “Canto guerrero: Mangiñ y Külapang”. Weichapeyuchi ül: cantos de guerrero. Antología de poesía política mapuche. Ed. Paulo Huirimilla Santiago, Chile: LOM Ediciones, 2012.

Landowski, Eric. La sociedad figurada. Ensayos de sociosemiótica. México: Fondo de Cultura Económica, 1993.

Lienhard, Martín. “El cautiverio colonial del discurso indígena: los testimonios”. Del discurso colonial al proindigenismo. Ensayos de historia latinoamericana. Temuco: Ediciones Universidad de La Frontera, 1998. 5-28.

Lienlaf, Leonel. Se ha despertado el ave de mi corazón. Santiago, Chile: Editorial Universitaria, 1989.

Lincomán, José Santos. "Poemas y Relatos de un Lonko williche José Santos Lincomán Inicheo" 69-128. Consejatu chafün williche. Poesía Mapuche. Las raíces azules de los antepasados. Tachi kallfüküpanngen ta pu kuyfikeche. Eds. Mabel García y Silvia Galindo. Universidad de La Frontera. Temuco, Chile: Editorial Florencia, 2004.

Loncón, Ricardo. "Por la razón o la fuerza" (Texto inédito autorizado por su autor), 2002.

Marimán, José. Autodeterminación. Ideas políticas mapuche en el albor del siglo XXI. LOM Ediciones, 2012.

Mignolo, Walter. Desobediencia epistémica: retórica de la modernidad, lógica de la colonialidad y gramática de la descolonialidad. Buenos Aires: Ediciones del Signo, 2010.

Mora Curriao, Maribel. "De versos y voces: ül registrados y poesía mapuche contemporánea”. En Kümedungun/Kümewirin. Antología poética de mujeres mapuche (siglos XX-XXI) de Maribel Mora y Fernanda Moraga. LOM Ediciones, 2010.

Parekh, Bhikhu. "El etnocentrismo del discurso nacionalista”. La invención de la nación. Lecturas de la identidad de Herder a Homi Bhabha. Buenos Aires, Argentina: Manantial, 2000. 91-122.

Pinto, Jorge. La formación del Estado y la nación, y el pueblo mapuche. De la inclusión a la exclusión. Santiago, Chile: Ediciones de la Dirección de Bibliotecas, Archivos y Museos, 2003.

Quintupill, Erwin. Las distancias. Versión digital difundida por su autor vía email, 2010.

Renan, Ernest. “¿Qué es una nación?” (1882.) La invención de la nación. Lecturas de la identidad de Herder a Homi Bhabha. Buenos Aires, Argentina: Manantial, 2000. 
FUENTES DigitALES:

Coordinadora Arauco Malleco. (CAM). "Comunicado Público. 13 de enero de 2013. http:// www.elclarin.cl/web/index.php?option=com_content\&view=article\&id=7054 14/05/2013]

Linco, Karla. "Resiste Señor Kintuante” http://tiamatkarlita.blogspot.com/2011/11/kintuanteresiste.html [25 abril de 2013]

Mariátegui, José Carlos. "El proceso de la literatura" (1928). 7 Ensayos de Interpretación de la Realidad Peruana. Edición Marxists Internet Archive, mayo de 2010. https://www. marxists.org/espanol/mariateg/1928/7ensayos/07.htm 24 de mayo de 2013]

O'Higgins, Bernardo. Carta. 13 de marzo de 1819. Prensa Oficina Parlamentaria. Anexo: Carta de O'Higgins. http://www.mapuche.info/print.php?pagina=1046 20 de Marzo de 2013]

Quintupill. Erwin. "Homenaje a Jaime Mendoza Collío. Confesiones necesarias”. http:// poesiamapuche.blogspot.com/2009/08/confesiones-necesarias.html [25marzo 2013] 